\title{
RESENHA DO FILME NA QUINTA COM KALLY, REALIZAÇÃO DE OTÁVIO RAPOSO
}

Leonardo Palhano Cabreira ${ }^{1}$

Plano aberto. Mural de arte urbana. Sonoridade ambiente. Assim se inicia Na Quinta com Kally, premiado ${ }^{2}$ curta etnográfico do antropólogo brasileiro radicado em Lisboa (Portugal) Otávio Raposo. Produzido em Portugal, no ano de 2019, e totalizando 27 minutos, esta obra contou também com a participação do realizador Filipe Ferraz, parceiro de Raposo nesta empreitada. Elaborado, assim, a partir de um projeto de pesquisa que tem por objetivo o desvelamento das fronteiras que intersectam a Arte e a Política, com atenção especial aos "novos horizontes de cidadania", este potente filme etnográfico exacerba o contexto português de requalificação de bairros sociais que passaram a sofrer impactos com megaprojetos de arte urbana, nos quais a street art é encarada como ferramenta de valorização de áreas consideradas "problemáticas", , como o era a Quinta do Mocho, localidade situada na periferia de Lisboa.

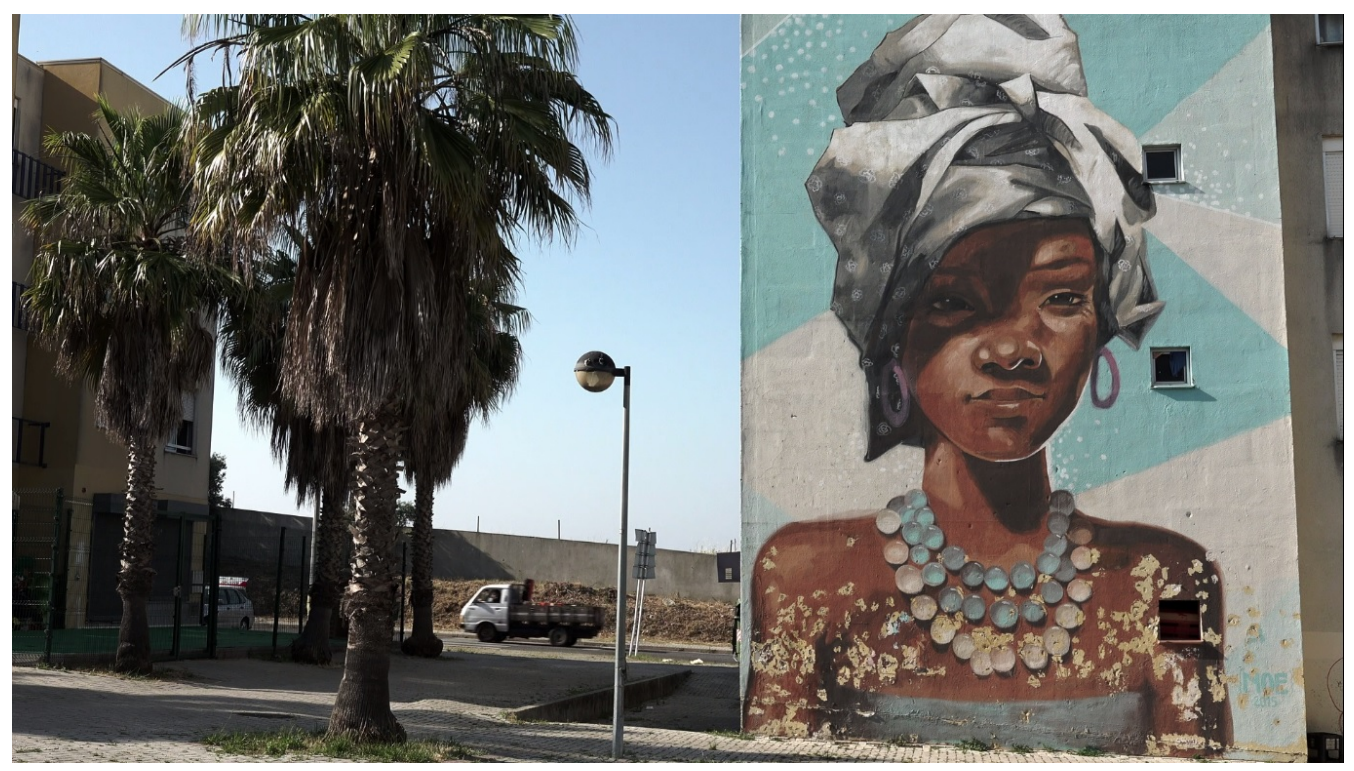

Fragmento visual 1 do filme etnográfico Na Quinta com Kally - Minuto 00:08

\footnotetext{
${ }^{1}$ Universidade Federal do Rio Grande do Sul, Brasil.

${ }^{2}$ Vencedor do Prémio APA 2018/2019 "Margot Dias e Benjamim Pereira" (Antropologia da Imagem e do Som) na Categoria I - Filme Etnográfico. Para mais, acesse:

http://artcitizenship.fcsh.unl.pt/2019/05/07/documentario-na-quinta-com-kally-vence-premio-apa-2018$2019 /$

${ }^{3}$ Como afirma um interlocutor no decorrer da película.
} 
Acompanhando o cotidiano de Kally, Ema (ativistas da arte urbana) e seu filho, a obra de Otávio Raposo nos leva a percorrer conjuntamente os circuitos de arte urbana por eles indicados, locais onde se encontram obras de artistas dos mais variados cantos do mundo, e que constituem uma das maiores galerias de arte a céu aberto da Europa. Estes sujeitos, assim, são apresentados no curta-metragem como guias locais de arte urbana, atividade que promovem na medida em que residem nos locais planejados para os circuitos e que, por conta da proximidade com os artistas no processo de produção das obras, apresentam estes grandes murais artísticos aos turistas e os explicam através das significações empreendidas pelos próprios criadores. Além disso, este filme etnográfico nos mostra que estes moradores locais também se articulam na produção de bens para consumação, além da disposição de espaços de lazer, levando-nos a compreender a importância de suas promulgações econômicas próprias. Assim, através da dinamização de um projeto de visitas ao bairro, entendemos que as trajetórias dos sujeitos da Quinta, em especial Kally, Ema e seu filho, estão interligados com a reinvenção desta localidade em seu destacado potencial artístico, cultural e social.

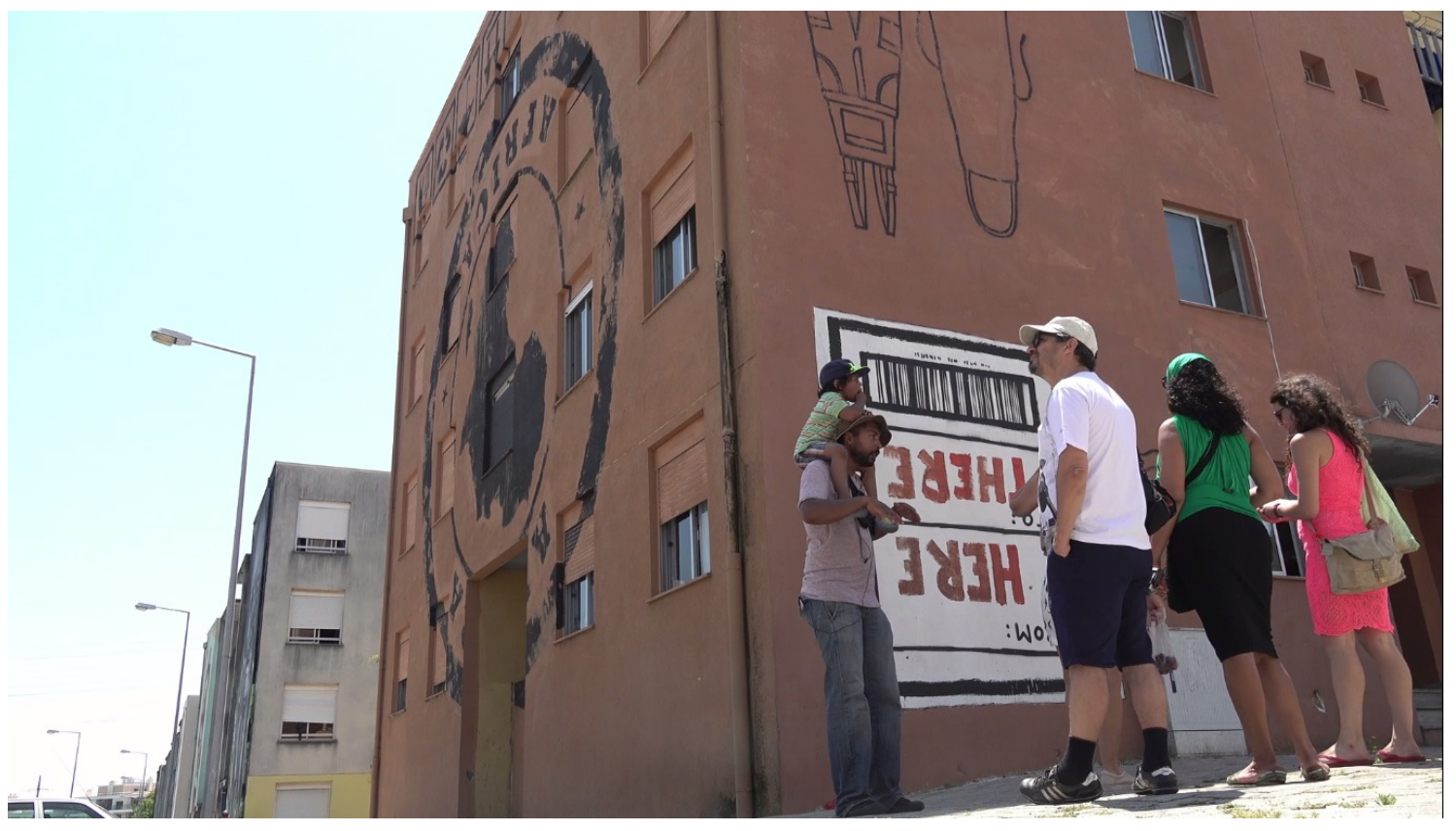

Fragmento visual 2 do filme etnográfico Na Quinta com Kally - Minuto 08:59

Com uma sutileza característica, somos convidados a conhecer também um pouco da Quinta do Mocho, localidade apresentada como um bairro de imigrantes bastante discriminados socialmente, onde $80 \%$ da população se encontram em situação de 
desemprego ${ }^{4}$. Uma das saídas que enxergaram para escapar deste cenário difícil fora justamente, em parceria com a Câmara Municipal da cidade de Loures (Distrito de Lisboa), abraçar o projeto de galerias de arte urbana em bairros sociais e embarcar numa empreitada turística proveitosa para eles ${ }^{5}$. Como Kally relata no decorrer da produção fílmica, os turistas chegam ao bairro sob o pretexto de uma visita guiada de arte urbana, mas em determinado momento os assuntos se cruzam e o interesse passa a ser também sobre as questões ligadas à comunidade. Assim, antes caracterizado por aspectos de ordem negativa, a Quinta tornou-se um celeiro ativo de produção cultural, destacando seus moradores como os principais responsáveis pela criação de coletivos culturais que valorizam o bairro.

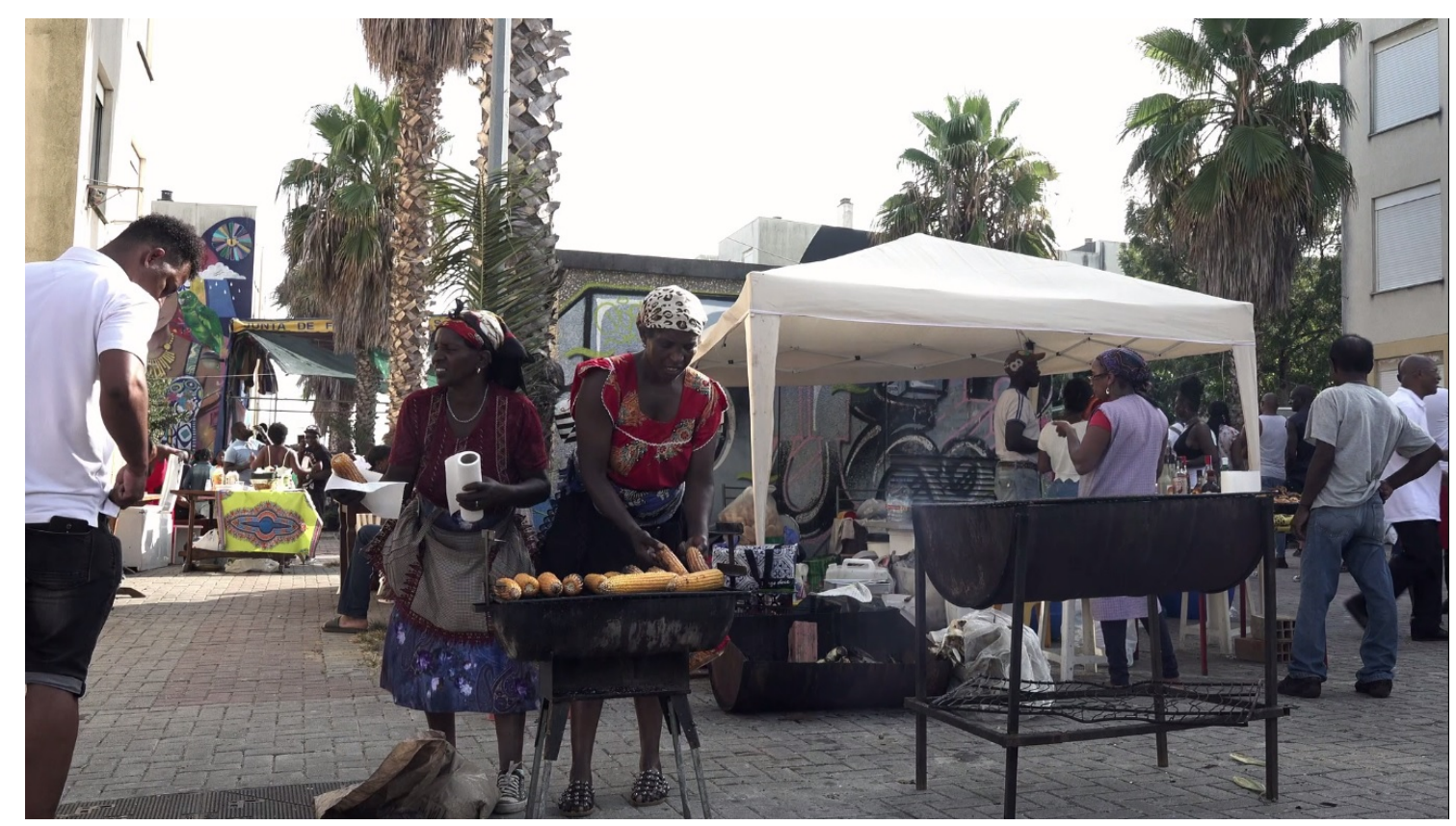

Fragmento visual 3 do filme etnográfico Na Quinta com Kally - Minuto 22:44

Se análises recentes refletem que o progressivo interesse de revitalizar e $\operatorname{artificar}^{6}$ localidades por via da street art e da urban art podem estar criando condições para a gentrificação $^{7}$ destes espaços, o filme de Otávio Raposo parece apontar para uma direção oposta, ao menos no nível do discurso. Saboreemos a fala de um morador local, interlocutor

\footnotetext{
${ }^{4}$ Segundo Kally, dos $20 \%$ que trabalham, $15 \%$, praticamente, são mulheres, que saem “às 4,5 e 6 da manhã para fazer faxina em Lisboa". Os homens, por serem antigos profissionais do ramo da construção civil, hoje não encontram mais trabalho.

${ }^{5}$ Os conflitos com o poder público, todavia, se exacerbam em outros trabalhos, dentre eles o de Otávio Raposo (2018).

${ }^{6}$ Sobre artificação, os estudos de Shapiro (2007) e Shapiro e Heinich (2013) são centrais.

${ }^{7} \mathrm{O}$ exemplo do Wynwood Walls, em Miami, é um caso bastante significativo deste cenário.
}

Iluminuras, Porto Alegre, v. 20, n. 50, p. 330-333, julho, 2019. 
no filme e proeminente figura daquele bairro: "Hoje em dia meu bairro é local turístico, antigamente era um local problemático, era um local que ninguém queria pisar e hoje toda gente quer pisar no meu bairro. E eu fico contente por isso". Notamos, assim, que são os próprios moradores que aparecem como os agentes de divulgação da comunidade, da Quinta, promovendo uma requalificação discursiva por meio de promulgações culturais próprias.

\section{Referências:}

RAPOSO, Otávio. "Guias da periferia: usos da arte urbana num bairro precarizado de Lisboa”. In: Gonçalves, Renata de Sá; Ferro, Lígia (Org). Cidades em mudança: processos participativos em Portugal e no Brasil. Editora Mauad (Livros Digitais), 2018.

SHAPIRO, Roberta. “Que é artificação?” In: Revista Sociedade e Estado, Brasília, v. 22, n. 1, p. 135-151, Janeiro/Abril. 2007.

SHAPIRO, Roberta; HEINICH, Nathalie. "Quando há Artificação?” In: Revista Sociedade e Estado, Brasília, v. 28, n. 1, p. 14-28, Janeiro/Abril. 2013.

Recebido 26/06/2019

Aprovado 24/07/2019 